Realino Marra. Es catedrático de Filosofía del Derecho y de Sociología del Derecho y de las Profesiones Jurídicas en el Dipartimento di Giurisprudenza, además de ser Decano de la Scuola di Scienze Sociali de la Università di Genova. Licenciado en Derecho por la Università di Bologna (1980). Ha estudiado y trabajado en las Universidades de Saarland (Alemania) y de Basilea (Suiza). Es director de la colección de la licenciatura en Servizio sociale (Giappichelli, Torino) y de "Diritto e realtà. Collana di sociologia giuridica" (Ledizioni, Milano). Es codirector de la revista "Materiali per una storia della cultura giuridica", fundada por Giovanni Tarello. Ha investigado sobre el realismo jurídico, el pensamiento de Comte, Durkheim, Tarde, Weber, Jellinek, Poincaré, Merton, Parsons, Foucault, sobre anomia y suicidio, sobre historia del derecho del trabajo, sobre derecho y literatura. Sus principales publicaciones son Suicidio, diritto e anomia (Napoli, 1987); Capitalismo e anticapitalismo in Max Weber (Bologna, 2002); La religione dei diritti. Durkheim - Jellinek - Weber (Torino, 2006); Diritto e castigo. Immagini della giustizia penale: Goethe, Manzoni, Fontane, Gadda (Bologna, 2013).

Contacto: realino.marra@giuri.unige.it 


\title{
Religiones y proceso de racionalización en Max Weber
}

\author{
Realino Marra \\ Università degli Studi di Genova
}

Fecha de recepción 15 de septiembre 2014; fecha de aceptación 20 de octubre 2014. El artículo es fruto de un proyecto de investigación desarrollado en el Dipartimento di Giurisprudenza de la Università degli Studi di Genova.

\section{Resumen}

Este ensayo está dedicado a la Zwischenbetrachtung (1915-6) de Max Weber, obra fundamental para la comprensión de toda su sociología de la religión. En particular, Marra se ocupa del típico tema weberiano de la tensión entre los procesos de racionalización relacionados con la desilusión (Entzauberung) con las bases mágico-religiosas originarias; y de las relaciones que las religiones de redención (Erlösungsreligionen) desarrollan, para Weber, con la economía y el poder.

\section{Palabras clave}

Weber, religión, racionalización, economía, política.

\section{Abstract}

The essay is dedicated to Max Weber's Zwischenbetrachtung (1915-16), a fundamental text for the comprehension of his whole sociology of religion. Marra focuses particularly on the theme, typical of Weber, of the tension between rationalization processes connected to the disenchantment (Entzauberung) and the original magical-religious foundation; he also discusses the relationships which the religions of redemption (Erlösungsreligionen), according to Weber, develop with economy and power.

\section{Keywords}

Weber, religion, rationalization, economy, politics. 


\section{Premisa}

¿Qué ocurre cuando unas creencias mágicas son reemplazadas por creencias más específicamente religiosas? Pues, dos cosas: casi siempre la religión tiende a ocasionar una colocación racional más o menos intensa de las conductas de vida; y, por consiguiente, ella se relaciona aún más directamente con los ordenamientos del mundo (con la esfera económica, política, estética, erótica, intelectual). Estas son las motivaciones fundamentales de la llamada Zwischenbetrachtung (Consideración intermedia) publicada por Max Weber en 1915-16 en el Archiv für Sozialwissenschaft und Sozialpolitik, y luego insertada en el primer volumen de los Gesammelte Aufsätze zur Religionssoziologie, en 1920. Se trata de un ensayo importante -para los especialistas y no solo- porque representa una inestimable clave para interpretar en su totalidad la sociología de las religiones de Weber. ${ }^{1} \mathrm{Al}$ mismo tiempo -y quizá precisamente por esta razón -, tal ensayo se presenta como un texto complejo, extremadamente condensado, tal vez el más enigmático de la producción weberiana.

Las páginas que se presentan a continuación quieren releer el ensayo con un dúplice propósito de reconstrucción: analizar el típico tema weberiano de la tensión entre los procesos de racionalización relacionados con la desilusión y los fundamentos religiosos originarios; considerar de manera conjunta las relaciones que las llamadas religiones de redención -para Weber- desarrollan con la economía y el poder. Sin embargo, se considerarán también otros ensayos de la Religionssoziologie, a partir -claro está- del más famoso de todos (Die protestantische Ethik und der Geist des Kapitalismus).

\footnotetext{
1. La literatura sobre la Religionssoziologie weberiana es inmensa; nos limitamos a recordar la fundamental contribución de Wolfgang Schluchter en los dos volúmenes de Religion und Lebensführung, Suhrkamp, Frankfurt a. M., I-II, 1988, y las dos recopilaciones por él editadas: Max Webers Studie über das antike Judentum. Interpretation und Kritik, Suhrkamp, Frankfurt a. M., 1981; Max Webers Studie über Konfuzianismus und Taoismus. Interpretation und Kritik, Suhrkamp, Frankfurt a. M., 1983; Max Webers Studie über Hinduismus und Buddhismus. Interpretation und Kritik, Suhrkamp, Frankfurt a. M., 1984; Max Webers Sicht des antiken Christentums. Interpretation und Kritik, Suhrkamp, Frankfurt a. M., 1985. Véanse también los prólogos a los tomos de la Religionssoziologie hasta ahora aparecidos en la weberiana Gesamtausgabe: Die Wirtschaftsethik der Weltreligionen. Konfuzianismus und Taoismus. Schriften 1915-1920, H. Schmidt-Glintzer, P. Kolonko (eds.), Mohr, Tübingen, 1989, pp. 1-25; Die Wirtschaftsethik der Weltreligionen. Hinduismus und Buddhismus. Schriften 1916-1920, H. Schmidt-Glintzer, K.-H. Golzio (eds.), Mohr, Tübingen, 1996, pp. 1-21; Die Wirtschaftsethik der Weltreligionen. Das antike Judentum. Schriften und Reden 1911-1920, E. Otto, J. Offermann (eds.), Mohr, Tübingen, 2005, pp. 1-144. Y en italiano Pietro Rossi, Max Weber. Una idea di Occidente, Donzelli, Roma, 2007, sobre todo la segunda parte del volumen, Il processo di razionalizzazione, pp. 115-232.
} 


\section{Religión y magia}

Para Weber, magia y religión no se diferencian por un rasgo específico de las creencias en los dos ámbitos; en los dos casos, ellas tienden a localizar una esfera de lo sagrado separada del mundo humano. Más bien, la que es diferente es la más avanzada y racional finalidad de las prácticas y de los preceptos relacionados con ellas. En particular, la religión intenta construir en el adepto un estado de ánimo más estable y duradero que lo convierta relativamente en menos atacable por el sufrimiento.

En lugar del estado de ánimo sagrado, logrado de manera aguda y extraordinaria, pero también transitoria, por medio de la orgía, de la ascesis o la contemplación, por parte de los creyentes era menester alcanzar un hábito sacro duradero, pues, como para tranquilizarlos acerca de su salvación: hablando en términos abstractos, esta era la finalidad racional de la religión de redención. ${ }^{2}$

Las religiones poseen un objetivo racional, es decir, la "redención” en el sentido más intensamente terrenal que Weber, más o menos establemente, atribuye al término ${ }^{3}$. Por lo tanto, no solo en el budismo la redención se concibe como liberación de la infelicidad; también en otras partes, detrás de los discursos sobre la purificación del pecado y sobre la reconquista de la "verdadera" vida, aquella sobrenatural, es necesario entrever el prevaleciente propósito de salvación del sufrimiento. La finalidad de redención es común -aunque con formas e intensidades diferentes- a casi todas las grandes religiones universales (hecha excepción solo del confucianismo, que considera "el mundo [como] el mejor de los mundos posibles”, ${ }^{4}$ de ahí que lleve a una ética de confirmación y no de perfeccionamiento y rescate), y es precisamente el elemento que se ha ocupado de emanciparlas de las antiguas premisas mágicas. La falta de un destino racional facilita el hecho de que la magia se presente con caracteres de religiosidad "exterior", ritualista; al mismo tiempo, las verdaderas religiones -siendo religiones de redención- se dirigen

\footnotetext{
2. M. Weber, "Zwischenbetrachtung: Theorie der Stufen und Richtungen religiöser Weltablehnung”, en Id., Die Wirtschaftsethik der Weltreligionen. Konfuzianismus und Taoismus, p. 484.

3. Por lo que a la construcción del tipo ideal de Erlösungsreligion se refiere, Weber se basa fundamentalmente en el Lehrbuch der Religionsphilosophie (Mohr, Freiburg-Leipzig, 1893) del filósofo Hermann Siebeck (1842-1921; con respecto a eso, véase la documentada "Introduzione" de Hans G. Kippenberg a M. Weber, Economia e società. Leconomia in rapporto agli ordinamenti e alle forze sociali. Comunità religiose, trad. de M. Palma, Donzelli, Roma, 2006, pp. CXXXIII-CXXXVII). 4. M. Weber, "Resultat: Konfuzianismus und Puritanismus", en Id., Die Wirtschaftsethik der Weltreligionen. Konfuzianismus und Taoismus, p. 451.
} 
hacia la búsqueda de bienes de salvación, religiosos en sentido "interior" (innerliche religiöse Heilsgüter). ${ }^{5}$

Del mismo modo, la misma religión guarda una velada relación con la magia y, pues, con el principio irracional de su naturaleza. Esto se destaca sobre todo en las circunstancias determinantes para su alejamiento de la magia. De la directa confrontación con la magia procede el impulso decisivo hacia formas de religiosidad más elevadas cuando, por ejemplo, se quiera neutralizar los efectos de una magia "mala", o bien cuando se necesite reaccionar ante un sistema de creencias cristalizadas y se considere necesario el hecho de que ellas deben ser superadas por medio de la acción de nuevas y más poderosas cualidades mágicas. Para Weber, esta segunda hipótesis es la más importante desde un punto de vista histórico-evolutivo, puesto que produce el acontecimiento decisivo en las más importantes religiones de la redención, es decir, su acta de fundación por medio de la acción y la predicación de un profeta o de un salvador. ${ }^{6}$ Por lo general, ambos se legitiman con la posesión de un carisma mágico, como en el caso de magos o sacerdotes. Es más, el hecho de recurrir al carisma y a las acciones y comportamientos dirigidos a su mantenimiento, se convierte cada vez más conscientemente en un "recurso" irracional para proporcionar respeto al ejemplo o a la misión del profeta, o bien para favorecer la identificación de un individuo como salvador. Cuanto más los objetivos de la fundación son ambiciosos más la irracionalidad del carisma está marcada; profeta y salvador se presentan (deben presentarse) como potencias revolucionarias antitéticas respecto de las hierocracias de la tradición. Sin embargo, el destino de la acción carismática -consistiendo en una acomodación de los comportamientos de la vida en vista de la salvación- se impone como racional con otra tanta intensidad. Por supuesto, todo esto proporciona una tensión latente a la labor del profeta y del salvador, entre revolución y organización, entre la forma de la predicación y sus objetivos. Sin embargo, aunque cuando se realice la fundación de una comunidad religiosa, está claro que la energía del carisma deberá agotarse, el cuidado de la reglamentación de los comportamientos se transfiere progresivamente a los sucesores (discípulos y aprendices), proporcionando -de tal manera- las condiciones para la afirmación de una nueva hierocracia. ${ }^{7}$

Por lo tanto, para Weber, magia y religión son diferentes etapas evolutivas de una base pues común, es decir, una creencia difundida en la existencia de una dimensión sobrenatural. La tentativa de elaborar tales representaciones con relación a objetivos

5. M. Weber, “Zwischenbetrachtung”, p. 485.

6. Ibid., pp. 483-484.

7. Ibid., p. 484. 
de redención es el factor decisivo del proceso de transformación racional de la magia. En su búsqueda constante, ella se enfrenta de manera cada vez más extensa y compleja a los ordenamientos del mundo, perdiendo pues sus caracteres originarios. Sin embargo, no por eso magia y religión expresan dos formas mentales opuestas entre sí (como se destaca en la teoría de Frazer), ${ }^{8}$ pues ellas se diferencian precisamente por la presencia o ausencia de aquellas intenciones racionales de las que hemos hablado, capaces de dirigir el ritualismo mágico hacia formas auténticamente religiosas. De manera consciente, la perspectiva de Weber sigue las huellas de la escuela inglesa y, sobre todo, de la obra de Robert Ranulph Marett con respecto a la evolución de todas las representaciones mágico-religiosas partiendo de una etapa preanimista (la creencia en una fuerza impersonal, el mana). ${ }^{9}$ Además de Weber, también parece interesante recordar que la perspectiva de Marett es bastante similar a la de Durkheim y de su escuela (la dimensión progresivamente social de las creencias mágico-religiosas es la dirección de su progreso evolutivo). ${ }^{10}$ Se trata de uno de los más significativos -aunque indirectos y desavisadosenlaces entre la sociología de la religión de Weber y la de Durkheim.

\section{Tipología de la ascesis y de la mística}

Por lo general, para Weber, las dos modalidades típicas de redención consisten en una búsqueda de salvación orientada en sentido ascético, en la cual la relación con el mundo es la prescripción de alguna manera de actuar que se considera querida por Dios, o bien en la posesión mística-contemplativa de la salvación que rechaza la acción y en la que, “el individuo no es instrumento sino 'florero' de lo divino”. En la mística, la relación con los ordenamientos sociales se acerca -de la manera más intensa- a la condición típico-ideal indicada por Weber como "rechazo del mundo".

Sin embargo, entre estos dos polos fundamentales existen diferentes niveles. La oposición más radical es la que se da entre ascesis intramundana, identificada por Weber prácticamente solo por el protestantismo calvinista de las sectas, y la contemplación mística como huida absoluta del mundo, típica sobre todo del budismo. En el primer

8. J. G. Frazer, The Golden Bough: a Study in Magic and Religion (1922), ed. with an introduction by Robert Fraser, Oxford University Press, London,1994.

9. Cfr. R.R. Marett, The Threshold of Religion, 1914, Methuen, London, 1979.

10. Cfr. É. Durkheim, H. Hubert, M. Mauss, Le origini dei poteri magici, Bollati Boringhieri, Torino, 2013; los enlaces entre la teoría preanimística y las orientaciones de los durkheimianos son subrayados claramente por Marett (también por lo que a este punto se refiere, véase H.G. Kippenberg, "Introduzione”, pp. CV-CVI). 
caso, la ascesis de la actuación se realiza "dentro del mundo, como su forjadora racional, con la finalidad de subyugar - por medio del trabajo en la "profesión" mundana- la corrupción creatural"; por lo contrario, en la segunda, lo místico considera el mundo como totalmente irracional, una amenaza para su estado de salvación. ${ }^{11}$ Dentro de estos dos extremos se hallan, pues, unas modalidades intermedias más o menos evidentes en varias vicisitudes de las religiones orientales (incluido el judaísmo antiguo que, para Weber, no se puede considerar una forma de religiosidad occidental), ${ }^{12}$ y también en aquellas del cristianismo. Por ejemplo, puede haber una mística que queda en el mundo e intenta adaptarse a sus preceptos por algunas razones de conveniencia práctica, aunque sin compartirlas; de la misma manera, pueden darse conductas ascéticas de tipo extra-mundano en las que la actuación se resume en prestaciones activas de redención, diferentes de aquellas prescritas por los ordenamientos sociales y consideradas más acordes a la voluntad divina.

Cualquiera que sea el tipo de impacto de la religión en la vida social (el rechazo coherente por parte de la mística, o bien -de lo contrario- la pretensión de dirección y control del protestantismo ascético), por consecuencia de este se produce otra implicación relevante. Ella es especular sobre a quella hasta ahora tomada en consideración, es decir, sobre los efectos de los ordenamientos sociales sobre la religión y está relacionada con la transformación que se produce en el mundo tras la confrontación con la religión. Para Weber, ambas direcciones proporcionan conflictos y tensiones. Por lo visto, por lo que a la primera se refiere, las creencias y las prácticas religiosas experimentan -de manera más o menos aguda y consciente- las contradicciones entre su existencia en el mundo y el núcleo esencial de los propios contenidos de fe. Por otra parte, actuando en el mundo lo transforman y, en particular, obligan las varias esferas de la actuación social (económica, política, estética, etc.) a confrontarse con la ética racional, por ellas desencadenada, respecto de los bienes de salvación. Casi siempre esto produce el efecto de sacar directamente a la luz -tras los preceptos religiosos que atañen a la vida socialla autónoma legalidad interna de las varias esferas hasta aquel momento más o menos latente. ${ }^{13}$

Pues entonces, la religión contribuye a hacer emerger otro aspecto fundamental del proceso de racionalización. Junto con la racionalización, digamos, interna -es decir,

11. M. Weber, "Zwischenbetrachtung", p. 482.

12. Esta es una de las razones principales del contraste con Sombart quien, diferentemente de Weber, en sus obras ha valorizado constantemente la contribución de la religión judía al desarrollo del capitalismo occidental (cfr. sobre todo W. Sombart, Der moderne Kapitalismus, Duncker \& Humblot, Leipzig, 1902).

13. M. Weber, "Zwischenbetrachtung", p. 485. 
aquella que atañe directamente a la religión y es responsable de su afrancamiento de la magia- también hay la racionalización externa, en la cual la religión actúa de manera indirecta, como una especie de agente involuntario aunque decisivo, favoreciendo la conciencia de la autonomía por parte de todas las demás formas de actuar. En primer lugar, autonomía respecto de las pretensiones de la religión pero también respecto de cualquier otro tipo de petición. Mientras la desilusión en sentido propio (Entzauberung), como emancipación de la magia, caracteriza a las principales religiones universales, la racionalización externa, en cambio, es propia de Occidente: y es precisamente el proceso de secularización paradójicamente favorecido también por la religión (en el sentido general que acabamos de considerar, y en relación con los acontecimientos específicos que analizaremos luego), con la afirmación global de una mentalidad racional bastante diferenciada en los variados ámbitos de la vida social (para Weber, esto puede favorecer ulteriores tensiones respecto de aquellas entre ordenamientos y religión). Los próximos dos párrafos analizarán los momentos fundamentales de la racionalización externa en relación con las religiones de redención, es decir, su vínculo con la esfera económica y política.

\section{Ética de la hermandad y economía racional}

Cuando las religiones se independizan de la influencia primitiva de la magia y se convierten en religiones sublimadas por la redención, se producen unos cambios importantes. Con la ruptura de los vínculos mágicos, se devalúan de manera progresiva o se ponen en tela de juicio las relaciones de parentesco natural; ahora, los nexos más importantes llegan a ser aquellos con el salvador, el profeta y el hermano en la fe. La comunidad social se vuelve a organizar y se transforma, por lo general adaptando a la nueva situación los principios del grupo del vecindario (la comunidad de la aldea, el grupo militar o de sustento alimenticio, etc.). Los preceptos característicos de las relaciones de vecindad, es decir, los deberes de solidaridad y reciprocidad, son consolidados por la idea de la redención. De ahí que se imponen unas reglas rigurosas de ayuda fraternal en caso de necesidad, de ayuda para los más débiles, de hospitalidad. Es más, la ética de la hermandad (Brüderlichkeitsethik), además de superar las barreras sociales internas en el grupo, puede tener consecuencias desde el punto de vista de la moral externa, como -por ejemplo- prescribir el amor hacia el hombre como tal y incluso hacia el enemigo. Desde un punto de vista práctico, la declinación universalística de la idea de 
hermandad puede conllevar -por ejemplo- unas restricciones más o menos significativas en la disciplina de los intercambios o de los préstamos, tal como la desaprobación de instituciones como la esclavitud. Al mismo tiempo, Weber tiende a considerar que, por lo general, siempre hay una línea de demarcación entre los deberes hacia el grupo y aquellos hacia otras comunidades; y que en algunos casos, la ética de la hermandad puede alejarse bastante de la moral "externa". ${ }^{14}$ Volveremos a hablar de esto.

Es muy importante -también desde el punto de vista político-social- el cambio psicológico que se produce en los individuos marcados por la redención; de hecho, es diferente la percepción del interés o de la ventaja individual que procede de la pertenencia a una comunidad religiosa. Por un lado, el bien supremo llega a ser -sin lugar a dudas- el sentimiento de la posesión inmediata de la comunión con Dios, un estado que proporciona la sensación de estar invadidos por la gracia y es el sentimiento de los elegidos o virtuosos. Por otro lado, esto no hace sino aumentar la distancia entre el valor subjetivo de la dimensión religiosa respecto de la idea de felicidad y bienestar propia de la condición de vida en las comunidades mágicas o mistéricas. En la religión popular china -tal como en aquella fenicia, védica o en los misterios eleusinos -la riqueza material formaba parte -junto con la salud, el honor, la descendencia- del bagaje ideal de una buena existencia individual. De lo contrario, por crear comunidades de hermanos, las religiones de redención manifiestan casi siempre gran aversión hacia una economía racionalizada, ya que ella produce una forma de vida abstracta e impersonal contraria a los ideales comunitarios. ${ }^{15}$

Para Weber, tal economía es sobre todo el capitalismo adquisitivo basado en el cálculo racional. De por sí, él necesita de la garantía de una doble libertad: antes que todo la del mercado, en el sentido de que los tráficos no deben ser limitados por monopolios u otros privilegios de clase; luego, la del trabajo, puesto que solo con la presencia de trabajadores que se entregan a la empresa de manera formalmente libre "los costes de producción pueden ser calculados de manera preliminar y precisa en la base de contratos de trabajo (Akkordsätze)". ${ }^{16}$ Además, siempre por lo que al cálculo del capital se refiere, han sido históricamente importantes también una contabilidad racional y la distinción cada vez más neta entre patrimonio de la empresa y patrimonio personal (es uno de los temas principales del primer libro de Weber, la Historia de las sociedades comerciales en

\footnotetext{
14. Ibid., p. 486.

15. Ibid., p. 487.

16. M. Weber, Wirtschaftsgeschichte. Abriß der universalen Sozial- und Wirtschaftsgeschichte. Mit- und Nachschriften 1919/20, W. Schluchter, J. Schröder (eds.), Mohr, Tübingen, 2011, p. 320.
} 
la Edad Media de 1889); ${ }^{17}$ el desarrollo científico de disciplinas útiles a las empresas técnicas racionales de cálculo y previsión, y un derecho y una administración valorables en la base de reglas formales. "Solo Occidente puso a disposición de la conducta económica similares derechos y administración con esta perfección técnico-jurídica y formalística". "Todo esto no estaba garantizado ni en la época de la polis griega, ni en los Estados patrimoniales asiáticos, ni en los Estados occidentales hasta los Stuart”. ${ }^{19}$

Ahora bien, similar desarrollo -que se ha realizado prácticamente solo en Occidente, y en el cual los vínculos personales casi siempre han sido sustituidos por relaciones objetivadas, que solo tienen en consideración, pues, las prestaciones y no la persona, las reglas del mercado y no aquellas de la comunidad- parece ser claramente incompatible con una coherente ética religiosa de la hermandad. Esta circunstancia está probada por la historia de los grandes sistemas religiosos orientales en los cuales siempre se puede notar -de manera más o menos intensa- el rechazo de aquellas actividades económicas que no preveen una disciplina ética de las relaciones de comunidad $y$, en particular, de aquellas entre hermanos en la fe. Solo en el judaísmo antiguo se distingue una mentalidad que intenta conciliar las relaciones religiosas con una actuación de tipo adquisitivo. Sin embargo, se trata de una forma capitalística seguramente no racional, afín a las economías especulativas o de atraco presentes en algunas fases de la edad antigua y, sobre todo, en la historia romana desde los últimos siglos de la República hasta el Principado, en la cual el poder económico -en virtud del estricto vínculo con la política- está en las manos de contratistas de impuestos y de grandes colonos demaniales. ${ }^{20}$ El dualismo entre moral interna y moral externa se da dentro del judaísmo de manera más patente que en otras partes, y en ámbito económico emerge de muchas determinaciones parenéticas de protección y de hermandad social, y también en la abierta admisibilidad de la usura hacia aquellos que son ajenos a la comunidad de fe. ${ }^{21}$

Entonces solo una religión, el protestantismo calvinista, demuestra haber tenido relaciones con el espíritu del capitalismo racional (como estilo de vida dirigido al trabajo profesional y a la búsqueda del beneficio por medio del cálculo). El origen de este

\footnotetext{
17. Véase M. Weber, Zur Geschichte der Handelsgesellschaften im Mittelalter. Schriften 1889-1894, Gerhard Dilcher, Susanne Lepsius (eds), Mohr, Tübingen, 2008, pp. 237-238.

18. M. Weber, "Die protestantische Ethik und der Geist des Kapitalismus”, en Gesammelte Aufsätze zur Religionssoziologie, Mohr, Tübingen, I, 1920, p. 11.

19. M. Weber, Wirtschaftsgeschichte, p. 319.

20. Cfr. sobre todo el segundo libro de Weber, de 1891: Die römische Agrargeschichte in ihrer Bedeutung für das Staats- und Privatrecht, J. Deininger (eds.), Mohr, Tübingen, 1986, pp. 207 ss.

21. M. Weber, Die Wirtschaftsethik der Weltreligionen. Das antike Judentum, pp. 700-701. Confróntese Deuteronomio, 23, 20-1: "No debes hacer que tu hermano pague interés [...]. Podrás hacer que un extranjero pague interés, a fin de que Jehová tu Dios te bendiga en toda empresa tuya en la tierra a la cual vas a tomar posesión de ella".
} 
contacto se remonta a la doctrina de la elección por medio de la gracia de Calvino, ${ }^{22}$ aunque esta -añade Weber- deba ser concebida como una consecuencia imprevista o inclusa no querida de la labor de los reformadores. ${ }^{23}$ Con la teoría de la predestinación se modifican -en sentido individualístico- las bases psicológicas de la pertenencia a la comunidad de fe. "A pesar de la necesidad, para lograr la salvación, de pertenecer a la verdadera iglesia, la relación del calvinista con su Dios se desarrolla[ba] en un profundo aislamiento interior (in tiefer innerlicher Isolierung) $).{ }^{24} \mathrm{El}$ puritano de las sectas sabe que el mundo debe ser útil a la autoglorificación de Dios y que, por lo tanto, él tiene unos deberes para alcanzar similar resultado. Sin embargo, en una religión de "predestinados a la verdadera vida", dentro de estas obligaciones no puede hallarse la realización de una hermandad indiscriminada sino, como mucho, el deber de servir el bien del género humano como una especie de "impersonal" utilidad social prescrita por Dios. ${ }^{25}$ Es la gran paradoja de la ética puritana que, como religión de los predestinados, renuncia a una idea fuerte de comunidad fraterna y objetiva, como un servicio prestado a la voluntad de Dios, solo una actuación racional en el mundo. De ahí que el universalismo del amor quede vaciado de sus imperativos de hermandad. La vida se considera sobre todo como compromiso y deber del individuo y, por otra parte, tienden a ponerse en marcha sentimientos de desprecio hacia los enemigos de Dios, cada vez más lejanos de las primeras aspiraciones de las mismas sectas puritanas dirigidas a recuperar el espíritu fraterno de los antiguos cristianos. A medida que el proceso madure, el calvinismo de las sectas deja de ser, pues, una auténtica religión de redención. ${ }^{26}$

Sin embargo, la tensión entre salvación religiosa y economía racionalizada puede tener otro resultado radical, opuesto al de la ascesis intramundana que acabamos de examinar. Es la substancial superación de la hermandad hacia el acosmismo del amor (Liebesakosmismus) que procede de la religiosidad mística extramundana, la búsqueda de una bondad impersonal, de la "bondad que, de una vez para siempre, regala también la camisa aunque hayan pedido solo la capa, a quien se halle por casualidad por la calle, y solo porque se encuentra por el camino". Para Weber, se trata de una forma peculiar de huida del mundo: ella practica una abnegación sin objeto, no por amor a alguien, sino por amor a la abnegación como tal. ${ }^{27}$

\footnotetext{
22. M. Weber, "Die protestantische Ethik", pp. 87 ss.

23. Ibid., p. 82.

24. Ibid., p. 97.

25. Ibid., pp. 99-101.

26. M. Weber, "Zwischenbetrachtung”, p. 490.

27. Por amor a la sagrada prostitución del alma, Weber concluye (ibid.) citando a Baudelaire (léase en Le spleen de Paris, XII, 1869), Les foules: “Il n'est pas donné à chacun de prendre un bain de multitude: jouir de la foule est un art [...] Ce que
} 
Pues bien, ambos itinerarios considerados, el ascetismo intramundano y la huida absoluta del mundo de la mística, de alguna manera logran substraerse de los preceptos éticos sobre el amor entre hermanos impuestos por las religiones sublimadas por la religión. El primero renunciando al universalismo del amor, la segunda transfigurándolo en un sentimiento indiferenciado e impersonal. Se trata de las soluciones más radicales y, por eso, relativamente más coherentes. Todos los demás caminos no pueden -para Weber-solucionar realmente la tensión. Ellos intentan -de cualquier forma-conciliar fe religiosa y presencia en el mundo, ética de la hermandad y aceptación de los ordenamientos sociales. Sin embargo, siendo el objetivo casi imposible si no se debilitan o anulan -tal como en los casos que hemos visto- los preceptos éticos relacionados con la redención, de hecho se producen soluciones de compromiso insatisfactorias y contradictorias, ${ }^{28}$ tal como ha ocurrido - por ejemplo- en el caso del monaquismo, que siempre ha puesto en práctica una ascesis extramundana. En este caso, se ha intentado crear formas de vida alternativas y respetuosas de los preceptos divinos, prohibiendo por ejemplo la propiedad individual del monje, imponiendo una existencia basada exclusivamente en su proprio oficio, limitando las necesidades a lo mínimo. Pero el tiempo le ha cogido la delantera; de hecho, por doquier monasterios y templos se han convertido en sedes de una economía racional. Y aún más disponibles para todo compromiso han sido - por su naturaleza- obviamente las místicas intramundanas (por ejemplo, con la organización de la mendicidad, como en India).

\section{Religiones y ordenamientos políticos}

Por lo general, otro tanto vivo es el conflicto entre los deberes de hermandad prescritos por las religiones de redención y los ordenamientos políticos. En una religiosidad de tipo mágico, la divinidad representa una estirpe o un reino particular, se confronta o bien se opone a divinidades similares, en la lucha con estas intenta afirmar su potencia, y combate, diríamos, junto con su grupo; pues bien, no puede haber contraposición con la guía política de la comunidad. De la misma manera en las divinidades de función: la

\footnotetext{
les hommes nomment amour est bien petit, bien restreint et bien faible, comparé à cette ineffable orgie, à cette sainte prostitution de l'âme qui se donne tout entière, poésie et charité, à l'imprévu qui se montre, à l'inconnu qui passe. (No a todos está permitido darse un baño de masas; gozar de la muchedumbre es un arte. [...] Lo que los hombres llaman amor es algo muy poco importante, limitado y débil, si lo parangonamos a esta inefable orgía, a esta sagrada prostitución del alma que se entrega totalmente, poesía y caridad, al inconveniente que se presenta, a lo ignoto que pasa)".

28. "Para una genuina ética de la redención, la tensión [...] era [...], en último término, difícilmente superable (kaum überwindlich)” (“Zwischenbetrachtung”, p. 489).
} 
protección de aspectos bien detectados de las actividades cotidianas difícilmente choca con asuntos de poder que emergen dentro del grupo. Por lo contrario, todo cambia con las religiones racionalizadas por la búsqueda de la salvación, sobre todo cuando -más coherentemente- hayan llegado a ser religiones que creen en un único dios, y cuando este dios prescriba el amor entre hermanos. Para Weber -tal como hemos notado- este es el camino típico de la racionalización "interna” a la esfera religiosa. Sin embargo, al mismo tiempo, la racionalización del ordenamiento político muy a menudo es diferente, es objetiva, burocrática e impersonal, similar a aquella que se manifiesta con el capitalismo en el ámbito de la actuación económica, es una actividad de confirmación (o de transformación) del poder sine ira ac studio, "sin respeto a la persona".

Efectivamente, el esquema de análisis se asemeja al que hemos visto en los ordenamientos económicos. Desde el punto de vista de las religiones de redención, la racionalización del mundo es diferente de la propia (“interna”); esta es de tipo material, expresa una fuerte necesidad de eticización de las relaciones de comunidad, mientras que la racionalización “externa” de las demás esferas - de la actuación económica con el capitalismo y de aquella política con el Estado burocrático moderno- es de tipo formal. Aunque aquí Weber no lo subraye de manera patente, aunque es evidente que él considera ambos fenómenos -capitalismo y Estado moderno- como los vértices evolutivos en los correspondientes ámbitos del proceso de racionalización que se ha realizado en Occidente (y solo en Occidente). Tampoco la distinción entre "racionalidad formal" y "racionalidad material" es explícita, pero emerge claramente de la globalidad de la argumentación; entre otras cosas, ella posee algunos contenidos similares a aquellos de otros pasajes de la producción weberiana (sobre todo de la Rechtssoziologie ${ }^{29}$ ).

Para cada grupo político es fundamental el llamamiento a la violencia de los medios coercitivos, tanto hacia el interior como hacia el exterior. En particular, el Estado es aquel grupo que exige para sí el monopolio de la violencia legítima; otra definición no es posible, añade de manera significativa Weber. "Al principio del Sermón de la montaña "no te opongas al mal con la violencia", él [el Estado] contrapone el principio: "tú debes procurar la victoria a la justicia también con la violencia” (auch mit Gewalt). ${ }^{30}$ De lo contrario, frente a una racionalización religiosa toda política despersonalizada y calculadora aparece en contraste con los deberes de la hermandad; por consiguiente,

29. M. Weber, “Die Entwicklungsbedingungen des Rechts”, en Id., Wirtschaft und Gesellschaft. Die Wirtschaft und die gesellschaftlichen Ordnungen und Mächte. Nachlaß, Teilband 2: Recht, W. Gephart-S. Hermes (eds.), Mohr, Tübingen, 2010, p. 303; sobre este punto, véase R. Marra, Max Weber: razionalità formale e razionalità materiale del diritto, en "Sociologia del diritto", XXXII-2/3, 2005, pp. 43-73.

30. M. Weber, "Zwischenbetrachtung”, p. 491. 
la patente naturaleza anética de las contiendas de poder impondría al fiel mantener el nombre de Dios lo más lejos posible de ellas.

Por otra parte, hay experiencias del conflicto entre política y religión que se alejan bastante de los contrastes de los que hemos hablado en el ámbito económico. En estos casos, el conflicto no brota de la radical oposición de los objetivos -ético en un caso (la hermandad) y pragmático en otro (la "razón de Estado" o una economía de tipo adquisitivo)-, sino más bien de la puesta en marcha de sentimientos y creencias de tipo irracional (o menos racional) capaces de competir con la religión. Weber piensa sobre todo en el caso de la hermandad bélica y de la muerte en guerra, similares a la experiencia del carisma sagrado y de la comunidad con Dios. En este caso, la política se presenta, pues, como directa competidora de la ética religiosa (eventualidad que, en cambio, no se da en los acontecimientos de la economía racional).

La guerra, como amenaza puesta en práctica del empleo de la violencia, crea [...] en las comunidades políticas modernas un pathos y un sentimiento de comunidad, y desarrolla, por lo tanto, [...] una abnegación y una comunidad de sacrificio incondicional (eine Hingabe und bedingungslose Opfergemeinschaft) en los combatientes, además de una obra de compasión y de amor hacia el necesitado que rompe todas las barreras del grupo natural. ${ }^{31}$

Tal vez valga la pena subrayar claramente que estas páginas fueron escritas a lo largo de los años de la Primera Guerra Mundial, y que en aquella ocasión el nacionalista Weber no solo había experimentado, sino también compartido con interés el pathos de la guerra. ${ }^{32}$ En ocasión de las guerras, la política elabora una especie de teodicea de la muerte alternativa a las justificaciones religiosas: la muerte no adquiere sentido y sacralidad respecto de un destino sobrenatural, sino para respaldar la dignidad autónoma de un grupo o de una nación. Respecto de una religiosidad de la hermandad, tal consagración intramundana de la muerte en guerra no puede sino aparecer como una especie de sacrílega justificación de un acto de fratricidio ${ }^{33}$.

También en ámbito político, para Weber solo hay dos soluciones coherentes a la tensión entre ética religiosa y ordenamientos del mundo, y son precisamente las mismas

\footnotetext{
31. Ibid., p. 492.

32. "Cualquiera que sea el resultado, esta guerra es grande y maravillosa ( $g r o ß$ und wunderbar)", escribe Weber cuando estalló la guerra mundial ("An Karl Oldenberg”, 28. August 1914, en M. Weber, Briefe 1913-1914, M.R. Lepsius-W.J. Mommsen, B. Rudhard-M. Schön (Eds.), Mohr, Tübingen, 2003, p. 782). 33. M. Weber, “Zwischenbetrachtung”, p. 493.
} 
identificadas a propósito de la actuación económica. Por un lado, el aristocraticismo de la salvación de la ascesis intramundana y, por otro lado, el aristocraticismo místico del acosmismo del amor. Son totalmente divergentes entre ellas, pero similares en cuando a los efectos se refiere. De hecho, ambas llevan a una retractación o a una radical transformación del deber de hermandad; además, ambas condenan el mundo social a una absoluta falta de sentido (o, por lo menos, condenan los objetivos de Dios con este relacionados a una total incomprensibilidad) ${ }^{34}$ Examinémolas de manera separada.

El particularismo de la gracia -típico de la ascesis profesional puritana-cree que es legítimo imponer con la violencia los mandamientos (al menos aquellos "comprensibles") de Dios en el mundo creatural. En particular, de este deriva la distinción entre "guerra santa", es decir, la guerra que se emprende para subyugar a los preceptos de Dios el mundo del pecado, y todas las demás iniciativas bélicas puramente mundanas.

De ahí que este rechazará -tal como hizo el triunfante ejército de los santos de Cromwell [...]- la coerción (Zwang) de participar en las guerras entre potencias políticas, no autorizadas por su propia conciencia, de las que no se sabe con certidumbre si son santas y si corresponden a la voluntad de Dios; y al servicio militar obligatorio preferirá el ejército mercenario. ${ }^{35}$

La guerra santa es un fenómeno que se halla también en el Islam, claro está; sin embargo -considera Weber-, en este caso tiene un carácter diferente. En la Zwischenbetrachtung, Weber no añade nada más. Pero no es difícil entender el sentido de su distinción, si se consideran sus análisis sobre el islamismo: la guerra del Profeta tiene objetivos antes que todo políticos, sirve para los intereses predatorios de las gentes guerreras, ${ }^{36}$ mientras que las guerras de los puritanos para él se presentan como guerras de religión en sentido propio, como hazañas de combatientes con una motivación fideística.

No solo diversa, sino totalmente opuesta es -para Weber- la posición de la religiosidad luterana. El cristianismo personal de Lutero posee una fuerte huella mística, y es por eso apolítica o directamente antipolítica. Este reconoce la autonomía de los ordenamientos mundanos, pero solo para sacar su naturaleza diabólica, o bien para adquirir hacia ellos actitudes de total indiferentismo ético (bien resumido por el principio "dad al César lo que es de César"). Rechazando la guerra por la fe y por el derecho de

34. Ibid., p. 497.

35. Ibid., pp. 494-495.

36. Cfr. M. Weber, "Einleitung”, en Id., Die Wirtschaftsethik der Weltreligionen. Konfuzianismus und Taoismus, p. 87. 
resistencia activa en contra de las agresiones de los poderes terrenales -tratándose de acciones que corromperían los imperativos de salvación con la aceptación del dogma de la violencia-, el luteranismo considera legítima solo la resistencia pasiva. Puesto que reconoce, a diferencia de la institución de la salvación universalística del catolicismo, la autonomía de los poderes mundanos, este prescribe el acatamiento a la autoridad también en la guerra, porque solo ella -y no el individuo- tiene la responsabilidad de esta. ${ }^{37}$

Sin embargo, la mística radical es aquella que se ha desarrollado sobre todo en Oriente, como huida total del mundo. Solo en el ámbito de estas prácticas es posible -para Weber- descubrir la otra verdadera solución del conflicto entre ética religiosa y política. La búsqueda mística de la salvación -junto con sus ideas de bondad y hermandad acosmística- se sustrae al dogma de la violencia actuando con un coherente antipoliticismo. Los mandamientos del mundo no tienen valor para quien no esté seguro de estar poseído por Dios; el que crea ser de tal manera redimido considera que las conductas, a partir de las suyas, no tienen ningún significado para la salvación. De hecho, la experiencia religiosa es el placer sublimado del propio carisma; el amor impersonal -en su esencia, todo menos que fraterno- solo es un medio de búsqueda de la redención.

Por lo general e inevitablemente, todas las demás tentativas de solución del conflicto proporcionan -precisamente como aquellas realizadas con respecto a la actuación económica- compromisos o limitaciones. Una de estas la hemos considerado antes, y es el luteranismo apolítico. La otra -de hecho más importante- es aquella de la ética social orgánica (organische Sozialethik). Con esta etiqueta, Weber indica experiencias diferentes; sin embargo, es evidente que -aunque sin nombrarlo- él quiera hacer referencia sobre todo al catolicismo. Ella es el resultado del envolvimiento de las religiones de redención con los intereses y las luchas políticas, respecto de exigencias de control de la población y de la necesidad para los poderes de recibir una consagración religiosa de su propia legitimidad. Por lo general, la ética social orgánica busca "considerar el mundo como un cosmos que contiene -a pesar de toda la corrupción del pecado- huellas del programa de salvación divino (göttlicher Heilsplan)". ${ }^{38}$ En particular, la reelaboración más significativa atañe a la justificación de las desigualdades sociales como algo permitido por Dios: a cada cual le tocan determinadas tareas dependiendo del carisma personal y de la situación económico-social establecida por el destino. Sobre todo en este esfuerzo de armonización del proyecto providencial respecto de las fortunas terrenales es evidente que la ética social orgánica lleva a una problemática-desde el punto de

37. M. Weber, “Zwischenbetrachtung”, p. 495.

38. Ibid., p. 497. 
vista de una genuina ética de la hermandad- "relativización de los valores de salvación religiosos y de su autónoma legalidad éticamente racional (ethisch rationale Eigengesetzlichkeit)".39

En fin, la ética social orgánica es natural y eminentemente conservadora, diferentemente de la religiosidad virtuosística que, en algunas circunstancias, puede presentar secuelas de carácter revolucionario. Resultados de este tipo se han dado en la ascesis intramundana, con la creación de un derecho natural divino contrapuesto a los ordenamientos corrompidos del mundo (hablaremos más detenidamente de esto dentro de poco). O bien, en la mística del rechazo del mundo, cuando el hecho de esperar un futuro comienzo de la hermandad acosmística puede transformar al virtuoso en un salvador o profeta. Sin embargo, los imperativos que él pronostica no tienen para nada un carácter racional; siendo productos inmediados de su carisma personal, ellos son revelaciones concretas, sin ninguna verdadera consecuencia para los ordenamientos del mundo. ${ }^{40}$

Totalmente diferentes son los efectos de la revolución puritana. Su renovación del derecho natural hacia los derechos representa una contribución específica y directa a la racionalización formal de los ordenamientos políticos, que se añade, pues -con efectos de potenciación-, a los impulsos autónomos visibles en el acontecimiento del nacimiento del moderno Estado burocrático. ${ }^{41}$ Por lo que al asunto de los derechos se refiere, como es notorio Weber comparte las tesis de Jellinek (presentes en las Erklärung der Menschen- und Bürgerrechte de 1895), ${ }^{42}$ integradas luego por Troeltsch. "Der Vater der Menschenrechte -escribe el segundo-ist also nicht der eigentliche Protestantismus, sondern das von ihm geha te und in die Neue Welt vertriebene Täufertum, worüber sich auch niemand wundern kann, der die innere Struktur des protestantisch-kirchlichen und des täuferisch-spiritualistischen Gedankens verstanden hat". ${ }^{43}$ En el nombre del principio "hay que obedecer a Dios antes que a los hombres" (Actos de los Apostóles: 5,29 ), las sectas calvinistas de las guerras de religión inglesas desarrollan una orientación rigurosamente antipolítica, que se transfiere luego a las pequeñas comunidades de iguales de las colonias de la Nueva Inglaterra. Aquí, los covenants coloniales, las islas, verdaderas anticipaciones de las declaraciones de los derechos de las revoluciones polí-

39. Ibid., p. 496.

40. Ibid., p. 499.

41. Sobre esto cfr. R. Marra, La religione dei diritti. Durkheim - Jellinek - Weber, Giappichelli, Torino, 2006, pp. 99-156.

42. G. Jellinek, Die Erklärung der Menschen- und Bürgerrechte (1895), Duncker \& Humblot, München-Leipzig, 1927.

43. E. Troeltsch, Die Bedeutung des Protestantismus fur die Entstehung der modernen Welt, in "Historische Zeitschrift", Bd. 97, H. 1, 1906, p. 40. 
ticas, establecen que la religión debe sustraerse de toda reglamentación en el nombre de la libertad de conciencia. De tal forma que los progresos antiinstitucionales del puritanismo de las sectas acercan el derecho natural del estado de pecado (el "derecho natural secundario", sucesivo al pecado original), al principio rígidamente conservador, al moderno y racionalístico derecho natural. Weber escribe (en Wirtschaft und Gesellschaft):

En el ámbito de la secta coherente surge [...] un "derecho" de los dominados [...] considerado imprescriptible [...] hacia el poder (Gewalt), ya sea político, hierocrático, patriarcal o de cualquier otro tipo. Prescindiendo del hecho de si - como, de manera persuasiva ha subrayado Jellinek - es el más antiguo, de todos modos, pues, la "libertad de conciencia" (Gewissensfreiheit) por lo general es el primer "derecho del hombre", siendo el más amplio, el que engloba en su plenitud la actuación éticamente determinada, que garantiza una libertad del poder, en particular del poder del Estado [... ]. A eso se añaden los demás "derechos del hombre”, "del ciudadano", o "fundamentales. ${ }^{44}$

Para Weber, los derechos son la herencia más significativa de la reforma puritana en el siglo de las revoluciones. La ilustración racionalística los vuelve a plasmar por lo menos en una doble dirección: en primer lugar, los transfiere desde el ámbito político al económico, desde las relaciones con el poder hasta aquellas del mercado de bienes y personas. En segundo lugar, los transforma en fundamento de todas las peticiones de igualdad jurídica formal, con tal de contribuir, de manera neta, al obscurecimiento de los contenidos de la fe religiosa del pasado. Desde este punto de vista, el protestantismo ascético no podía encontrar un ejecutor testamentario más radical.

Tales principios encuentran su justificación última (ihre letzte Rechtfertigung) en la creencia de la época ilustrada según la cual la "razón" del individuo, cuando se le dé libertad absoluta, en virtud de la providencia divina y del hecho de que el individuo conoce mejor que nadie sus propios intereses, puede proporcionar por lo menos un mundo relativamente mejor: por lo tanto, la transfiguración carismática (die charismatische Verklärung) de la "razón" (que encontró su expresión característica en la apoteosis llevada a cabo por Robespierre) es la última

44. M. Weber, Wirtschaft und Gesellschaft. Die Wirtschaft und die gesellschaftlichen Ordnungen und Mächte. Nachlaß, Teilband 4, Herrschaft, E. Hanke en colaboración T. Kroll, Tübingen, Mohr, 2005, pp. 678-679 (en el texto hemos modificado algo de la versión del traductor italiano). Compartía este pensamiento también Carl Schmitt: la libertad religiosa es "das erste allgemeine Grundrecht”, Verfassungslehre, Duncker \& Humblot, München-Leipzig, 1928, p. 158. 
forma que el carisma generalmente ha adquirido en su camino fatal (auf seinem schicksalsreichen Wege). Está claro que [las] exigencias (Forderungen) de igualdad jurídica formal y de libertad de movimiento económico por una parte prepararon la destrucción (Zerstörung) de todos los fundamentos específicos de los ordenamientos jurídicos patrimoniales y feudales en favor de un cosmos de normas abtractas, y pues de manera indirecta la burocratización, pero por otra parte -de manera muy específica- salieron en ayuda a la expansión del capitalismo".45

En consecuencia, para Weber, Robespierre se sustituye a Roger Williams, el deísmo del "ser supremo" reemplaza la ascesis intramundana.

Sin embargo, también por lo que a esto se refiere, se confirma lo excepcional del protestantismo ascético en la globalidad de la historia universal. Solo gracias a este $-y$ a la aportación sucesiva de la ilustración que cree en la naturaleza salvífica de la libertad de movimiento y de los intercambios- se realiza una completa racionalización "externa" del mundo, en el ámbito económico, con la afirmación del capitalismo y, en ámbito político, con el nacimiento de los ordenamientos impersonales del Estado burocrático construidos sobre la igualdad jurídica formal. Es la clave de bóveda de toda la sociología de la religión de Weber; dar al proyecto de la obra una evidencia ejemplar es realmente el objetivo fundamental de la Zwischenbetrachtung.

Traducción del italiano de M. Colucciello

45. M. Weber, Wirtschaft und Gesellschaft. Die Wirtschaft und die gesellschaftlichen Ordnungen und Mächte. Nachlaß, Teilband 4, p. 679 . 